\title{
Two Alzheimer's disease risk genes increase entorhinal cortex volume in young adults
}

\author{
Amanda Marie DiBattista ${ }^{1}$, Benson W. Stevens ${ }^{1,2}$, G. William Rebeck ${ }^{1}$ and Adam E. Green ${ }^{2 *}$ \\ ${ }^{1}$ Department of Neuroscience, Georgetown University Medical Center, Washington, DC, USA \\ ${ }^{2}$ Department of Psychology, Georgetown University, Washington, DC, USA
}

\author{
Edited by: \\ Aron K. Barbey, University of Illinois \\ at Urbana-Champaign, USA \\ Reviewed by: \\ Daniel Llano, University of Illinois at \\ Urbana-Champaign, USA \\ Edward Huey, Columbia University \\ in the City of New York, USA \\ *Correspondence: \\ Adam E. Green, Department of \\ Psychology, Georgetown University, \\ 37th and O Streets, NW, 302 C \\ White-Gravenor, Washington, DC \\ 20057, USA \\ e-mail: aeg58@georgetown.edu
}

\begin{abstract}
Alzheimer's disease (AD) risk genes alter brain structure and function decades before disease onset. Apolipoprotein $E$ (APOE) is the strongest known genetic risk factor for AD, and a related gene, apolipoprotein J (APOJ), also affects disease risk. However, the extent to which these genes affect brain structure in young adults remains unclear. Here, we report that $A D$ risk alleles of these two genes, APOE- -4 and APOJ-C, cumulatively alter brain volume in young adults. Using voxel-based morphometry (VBM) in 57 individuals, we examined the entorhinal cortex, one of the earliest brain regions affected in $A D$ pathogenesis. Apolipoprotein $\mathrm{E}-\varepsilon 4$ carriers exhibited higher right entorhinal cortex volume compared to non-carriers. Interestingly, APOJ-C risk genotype was associated with higher bilateral entorhinal cortex volume in non-APOE- $\varepsilon 4$ carriers. To determine the combined disease risk of APOE and APOJ status per subject, we used cumulative odds ratios as regressors for volumetric measurements. Higher disease risk corresponded to greater right entorhinal cortex volume. These results suggest that, years before disease onset, two key $A D$ genetic risk factors may exert influence on the structure of a brain region where AD pathogenesis takes root.
\end{abstract}

Keywords: APOE, APOJ, CLU, VBM, entorhinal cortex

\section{INTRODUCTION}

Multiple genetic polymorphisms have been shown to increase Alzheimer's disease (AD) risk without guaranteeing its onset (Bertram et al., 2007). Though the mechanisms of genetic risk are largely unknown, one possibility is that risk gene-dependent vulnerabilities and age-dependent vulnerabilities may interact to trigger neurodegeneration (Risacher et al., 2010; Reinvang et al., 2013). Genome-wide association studies have repeatedly shown that the $\varepsilon 4$ allele of the apolipoprotein $\mathrm{E}(\mathrm{APOE})$ gene is the strongest known genetic risk factor for $\mathrm{AD}$, increasing risk by $200-300 \%$ and decreasing age of onset, in a dose-dependent manner (Farrer et al., 1997; Bertram et al., 2007; Harold et al., 2009; Fei and Jianhua, 2013). A related risk factor, apolipoprotein $\mathrm{J}(A P O J$, also known as clusterin, CLU), also modestly increases $\mathrm{AD}$ risk, with the $A P O J-C$ risk allele increasing $\mathrm{AD}$ risk by 10-15\% (Harold et al., 2009; Lambert et al., 2009). These two $\mathrm{AD}$ risk genes encode similar proteins that associate with lipoproteins in the brain (Koch et al., 2001; Elliott et al., 2010) to interact with a shared family of cell surface receptors (Kounnas et al., 1995; Leeb et al., 2014) that promote neurite outgrowth (Nathan et al., 1994; Kang et al., 2005), cholesterol metabolism (for review, see Holtzman et al., 2012), and clearance of the $\mathrm{AD}$ pathological hallmark, amyloid- $\beta$ (Demattos et al., 2004).

Apolipoprotein $E$ genotype is associated with accelerated atrophy in the brain during disease progression (Shen et al., 2010), and the gray matter density in the medial temporal lobe (MTL) of
APOE- $\varepsilon 4$ carriers is particularly sensitive to this type of atrophy (Thomann et al., 2008; Fei and Jianhua, 2013). While the effect of APOE genotype on MTL atrophy has been well established in older adults, effects on the young brain are less clear. Whole brain analyses in healthy APOE- $\varepsilon 4$ carriers report increased (Alexander et al., 2012), decreased (Wishart et al., 2006; O'dwyer et al., 2012; Knickmeyer et al., 2013), or unchanged (Mondadori et al., 2007; Filippini et al., 2009; Dennis et al., 2010; Samuraki et al., 2012; Stein et al., 2012; Matura et al., 2014) MTL volume depending on the experimental parameters. Although less studied than APOE- $\varepsilon 4, A P O J$ was also not associated with MTL differences in a large scale genome-wide association study (GWAS) metaanalysis (Stein et al., 2012). As with APOE, it may be that more sensitive analyses are necessary to detect differences induced by $A P O J$ risk. Thus, our aim was to assay gray matter volume in a particular area of the MTL that is susceptible to AD pathology very early in the disease, the entorhinal cortex (Braak et al., 2011). The entorhinal cortex facilitates communication between the hippocampus and neocortex for memory consolidation. We sought to test whether $A P O E$ and APOJ genotypes affected entorhinal cortex volume in a cohort of young adults. In addition, the putative functional similarities between the proteins these genes encode (Kounnas et al., 1995; Koch et al., 2001; Elliott et al., 2010; Leeb et al., 2014) prompted us to explore whether APOE and $A P O J$ polymorphisms may have a cumulative effect, which would suggest the potential of a common pathway for these risk factors in a region critical for $\mathrm{AD}$ pathogenesis. 


\section{MATERIALS AND METHODS PARTICIPANTS}

Participants were healthy, right-handed university students and community members ( $n=57,33$ male, $74 \%$ Caucasian). Each participant provided informed consent for MRI and genotyping. These participants ranged from 18-35 years of age (mean = 21.8 , standard deviation $=4.0$ ) with no history of mental illness, psychoactive medication or brain injury. All procedures received IRB approval prior to the study.

\section{GENOTYPING}

We performed genotyping of the human APOJ (or CLU) polymorphism at rs11136000, human APOE polymorphism at rs429358 (codon 112), and human APOE polymorphism at rs7412 (codon 158) using the TaqMan assay (Applied Biosystems). A reaction volume of $25 \mu \mathrm{L}$ containing $50 \mathrm{ng}$ DNA, $5 \mathrm{~mL} \mathrm{MgCl} 2$ and $1 X$ TaqMan Universal PCR Master Mix containing AmpliTaq Gold DNA Polymerase was amplified using 40 cycles of $15 \mathrm{~s}$ at $95^{\circ} \mathrm{C}$ and $1 \mathrm{~min}$ at $60^{\circ} \mathrm{C}$. A total of $0.2 \mu \mathrm{M}$ of each of the sequencespecific probes $5^{\prime}$-6FAM ACCAAAGCCACACCAGCTATCAAA A[T]TCT CTAACGGGCCCTTGCCACTTGA-TAMRA- $3^{\prime}$ and $5^{\prime}$ VIC-ACCAAAGCCA CACCAGCTATCAAAA[C]TCTCTAACGG GCCC TTGCCACTTGA-TAMRA- $3^{\prime}$ were used in the allelic discrimination assay for APOJ. For the allelic discrimination assay for APOE, sequence specific probes were also used: $5^{\prime}$ VICCCGCGATGCCGATGACCTGCAGAAG [C]GCCTGGCAGTGT ACCAGGCCGGGGC-TAMRA-3' ${ }^{\prime}$ and 5'FAM-CCGCGATGCC G ATGACCTGCAGAAG[T]GCCTGGCAGT GTACCAGGCCGGG GC-TAMRA-3' for rs7412 and 5' VIC-GCTGGGCGCG GACATG GAGGACGTG[C]GCGGCCGCCTGGTGCAGTACCGCGG-TA MRA- $3^{\prime}$ and 5'FAM-GCTGGGCGCGGACATGGAGGACGTG[T] GCGGCCGCCTGGT GCAGTACCGCGG-TAMRA-3' for rs 429 358. Allele detection and genotype calling were performed using the ABI 7700 and Sequence Detection Software (Applied Biosystems). All calls scored at least $95 \%$ quality values and were verified by $100 \%$ recall on $\sim 20 \%$ of samples that were re-tested for quality control.

\section{IMAGE ACQUISITION, PROCESSING, AND ANALYSIS}

Magnetic resonance imaging images were acquired using a 3T Allegra System (Siemens, Erlangen, Germany). Whole-brain structural T1-weighted magnetization-prepared rapid gradientecho (MPRAGE) images were acquired for each subject (FOV $=256 \mathrm{~mm} ; 256 \times 256$ matrix; $1 \times 1 \mathrm{~mm}$ in-plane resolution, $1.25 \mathrm{~mm}$ thick axial slices, 1 average). All MPRAGE images were processed using SPM8 ${ }^{1}$ on MATLAB $2010 \mathrm{~b}^{2}$.

Voxel-Based Morphometry (VBM) was performed using the DARTEL toolbox for SPM (Ashburner and Friston, 2000; Ashburner, 2007). All default settings were used except where noted otherwise. Images were aligned into AC/PC orientation prior to segmenting into gray matter, white matter, and cerebrospinal fluid. All participants' gray and white matter images were then simultaneously registered together to create a study specific template to reduce between-participant variability. The

\footnotetext{
${ }^{1}$ http://www.fil.ion.ucl.ac.uk/spm/software/spm8/

${ }^{2} \mathrm{http}: / /$ www.mathworks.com/products/matlab/
}

template was then used to normalize all images into the standard Montreal Neurological Institute (MNI) space using the "DARTEL Normalize to MNI Space" program, utilizing the "preserve amount" option to retain the volumetric data of the original images. The images were smoothed using a Gaussian kernel with $8 \mathrm{~mm}$ full-width half maximum (FWHM). For statistical analyses, masks for the left and right entorhinal cortex were created from the Juelich Histological Atlas (Eickhoff et al., 2005). The mean gray matter volumes were then extracted from the participants MNI aligned gray matter images with both masks. Lastly, to account for global brain volume differences, intracranial brain volume for each participant was used to normalize extracted gray matter volumes. Intracranial brain volume was calculated by combining the total brain volumes found in native space gray matter, white matter, and cerebrospinal fluid images for each participant. Left $(p=0.3028, p=0.5027)$ and right $(p=0.2231, p=0.2118)$ extracted gray matter volumes for the entorhinal and primary visual cortex, respectively, were normally distributed according to the Shapiro-Wilk test; therefore, parametric statistics were conducted.

\section{RESULTS \\ GENOTYPING}

We isolated and purified DNA from 57 participants to genotype for two genes associated with increased risk of late onset $\mathrm{AD}$ : $A P O E$ and $A P O J$. The following numbers of subjects per group were included in analyses: $\varepsilon 2 / \varepsilon 2$ (2 subjects), $\varepsilon 2 / \varepsilon 3$ (6 subjects), $\varepsilon 3 / \varepsilon 3$ (40 subjects), $\varepsilon 3 / \varepsilon 4$ (9 subjects) (Table 1). Because the $\varepsilon 2$ allele is associated with a protective effect from $\mathrm{AD}$, analyses were conducted with and without $\varepsilon 2$-carriers. There were two subjects with the $\varepsilon 2 / \varepsilon 4$ genotype, and results from these two subjects were excluded from all analyses. The distribution of APOE genotypes was as expected for the United States, with allele frequencies of $0.064(\varepsilon 2), 0.783(\varepsilon 3)$, and 0.145 ( $\varepsilon 4)$ (Eisenberg et al., 2010). Of these subjects, there were $15 \mathrm{APOJ}-\mathrm{C} / \mathrm{C}$ subjects, $33 \mathrm{APOJ}-\mathrm{C} / \mathrm{T}$ subjects, and $9 A P O J-T / T$ subjects. Both of the excluded subjects with the $A P O E-\varepsilon 2 / \varepsilon 4$ genotype also had the $A P O J-C / T$ genotype, and were excluded from all analyses. The distribution of $A P O J$ genotypes was also as expected based on previous studies, with

Table 1 | Demographic information.

\begin{tabular}{|c|c|c|c|c|}
\hline Genotype & Sex & Age & $\begin{array}{c}\text { O.R. } \\
\text { APOE, APOJ }\end{array}$ & $\begin{array}{l}\text { Risk } \\
\text { score }\end{array}$ \\
\hline APOE-ع4/APOJ-C & $M: 5 ; F: 3$ & $19.8 \pm 1.5$ & $4.3,1.22$ & 1.657 \\
\hline $\begin{array}{l}\text { APOE-ع4/ } \\
\text { APOJ-non-C }\end{array}$ & $M: 1 ; F: 0$ & $19 \pm 0$ & $4.3,1$ & 1.459 \\
\hline $\begin{array}{l}\text { APOE-non- } 4 / \\
\text { APOJ-C }\end{array}$ & M: 21; F: 19 & $21.8 \pm 3.5$ & 0.6 or $1,1.22$ & 0.199 \\
\hline $\begin{array}{l}\text { APOE-non- } 4 \text { / } \\
\text { APOJ-non-C }\end{array}$ & $M: 6 ; F: 2$ & $23.8 \pm 6.9$ & 0.6 or 1,1 & 0 \\
\hline
\end{tabular}

Values for age represent the mean \pm standard deviation. Odds ratios (O.R.) are normalized to $A P O E-\varepsilon 3$ and non-APOJ-C, making these values "1." Risk scores shown are sums of the natural $\log$ of the odds ratios. Non-APOE- 4 group includes $A P O E-\varepsilon 2$ carriers that have O.R. of 0.6 . 


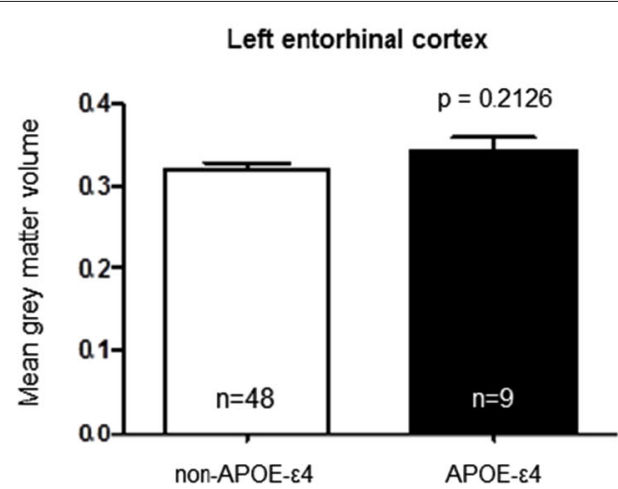

FIGURE 1 | Apolipoprotein $E-\varepsilon 4$ AD risk genotype is associated with greater right entorhinal cortex volume. A two-tailed t-test demonstrates that when participants are grouped based on $A P O E$ status alone, the risk

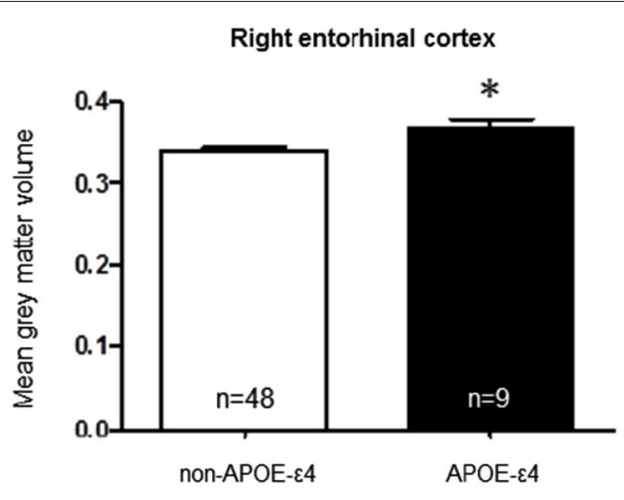

allele $(A P O E-\varepsilon 4)$ is associated with higher right entorhinal cortex volume compared to the non-risk alleles $t_{(55)}=2.29, p=0.0259$. ${ }^{*} p<0.05, n=48$ non-APOE- $\varepsilon 4$ carriers, $n=9$ APOE- $\varepsilon 4$ carriers).
FIGURE 2 | Apolipoprotein J-C AD risk genotype is associated with greater bilateral entorhinal cortex volume, in noncarriers of $\boldsymbol{A P O E}-\varepsilon 4$. A two-tailed $t$-test demonstrates that when non-APOE- $\varepsilon 4$ carriers are grouped based on APOJ status, APOJ-C

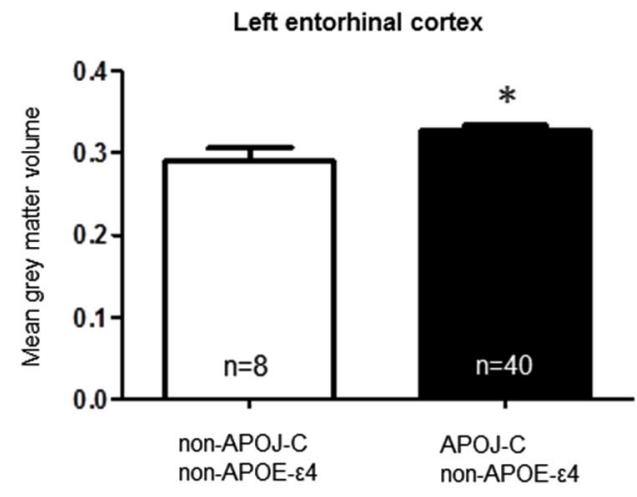

allele frequencies of $0.447(\mathrm{~T})$ and 0.553 (C) (Golenkina et al., 2010; Table 1).

\section{MRI}

To test the hypothesis that the APOE- $\varepsilon 4$ and $A P O J-C$ risk alleles alter the structure of a brain region affected early in AD pathogenesis (Hyman et al., 1984; Gomez-Isla et al., 1996; Braak et al., 2011), we extracted gray matter volumetric measurements within the left and right entorhinal cortical regions of interest for each genotype group. We then conducted a priori $t$-tests to interrogate the relationship of each polymorphism with entorhinal cortex volume. A comparison of $A P O E$ - $\varepsilon 4$-positive vs. APOE- $\varepsilon$ 4-negative individuals, collapsed across APOJ genotype, revealed significantly greater right entorhinal cortex volume for $A P O E-\varepsilon 4$ carriers by $8.47 \%, t_{(55)}=2.29, p=0.0259$ (Figure 1, $\left.{ }^{*} p<0.05\right)$. This effect persisted when APOE- 22 carriers were removed from analyses, $t_{(47)}=2.185, p=0.0339$. Differences in left entorhinal cortex volume in APOE- $\varepsilon 4$ carriers compared to non-carriers did not reach statistical significance, $t_{(55)}=1.261$, $p=0.2126$ (Figure 1). To examine the effect of APOJ-C in the absence of the APOE- $\varepsilon 4$ allele, we grouped non-APOE- $\varepsilon 4-$ carriers by $A P O J-C$ status (APOJ-C vs. non- $A P O J-C$-carriers). This comparison revealed that, among non- $A P O E-\varepsilon 4$-carriers, $A P O J-C$ carriers had greater left entorhinal cortex volume by $12.33 \%, t_{(46)}=2.05, p=0.0458$, and greater right entorhinal cortex volume by $8.16 \%, t_{(46)}=2.03, p=0.0485$ (Figure $2,{ }^{*} p<0.05$ ). This effect persisted when $A P O E-\varepsilon 2$ carriers were removed from analyses for the right entorhinal cortex $\left(t_{(38)}=2.03, p=0.0492\right)$, but not the left entorhinal cortex $\left(t_{(38)}=1.89, p=0.067\right)$.

Based on a putative shared biological pathway, we hypothesized that $\mathrm{AD}$ risk factors $A P O E-\varepsilon 4$ and $A P O J-C$ work together to alter brain structure in young adults. We explored the possibility of a combined effect of $A P O E$ and $A P O J$, although the interpretation is somewhat limited by the small number in one of the groups (APOE- $\varepsilon 4, A P O J$-non-C; Table 1). A $t$-test of the highest risk group (APOE- $\varepsilon 4, A P O J-C, n=8$ ) vs. the lowest risk group (non$A P O E-\varepsilon 4$, non- $A P O J-C, n=6)$ reveals that greater $\mathrm{AD}$ risk is associated with greater right entorhinal cortex volume by $13.89 \%$, 
Left Entorhinal Cortex

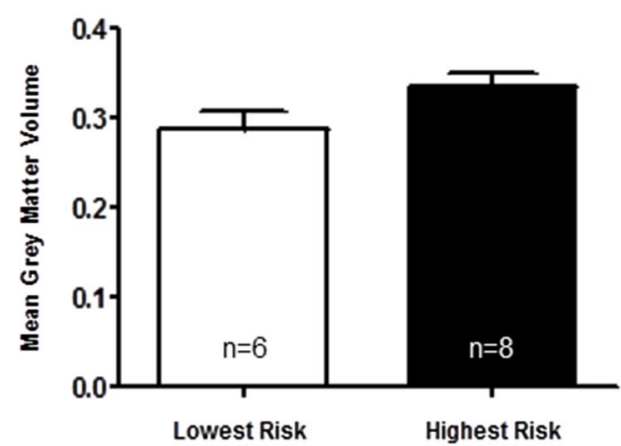

FIGURE 3 | Apolipoprotein $E$ and $A P O J$ risk genotypes show an additive association with greater right entorhinal cortex volume. A two-tailed $t$-test shows that when the highest risk group (APOE- $84, A P O J-C, n=8$ ) is compared to the lowest risk group
Right Entorhinal Cortex

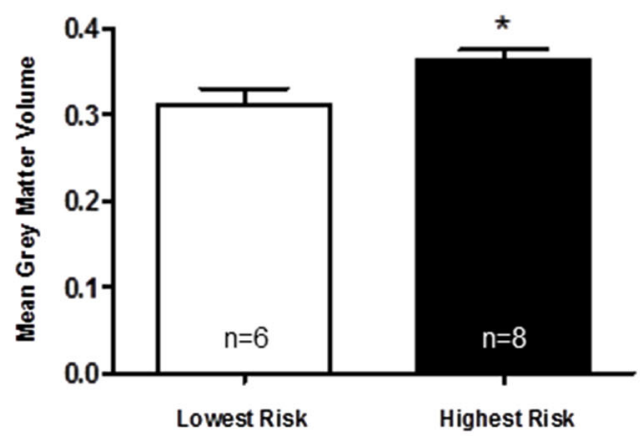

(non-APOE- $\varepsilon 4$, non-APOJ-C, $n=6$ ), greater $A D$ risk is associated with greater right entorhinal cortex volume by $13.89 \%, t_{(12)}=2.27$, $p=0.0421\left(^{*} p<0.05\right)$, but not left entorhinal cortex volume, $p>0.09$. $t_{(12)}=2.27, p=0.0421$, but no difference in left entorhinal cortex volume, $p=0.09$ (Figure $3,{ }^{*} p<0.05$ ). When including $A P O E-\varepsilon 2$ carriers in the analyses, this effect on the right entorhinal cortex persists, $t_{(20)}=2.12, p=0.0464$, without changing the effect on the left entorhinal cortex, $p>0.1$. To directly investigate the combined effect AD risk, we tested whether a "risk score" variable was predictive of entorhinal cortex volume. Risk score was weighted by each risk allele's odds ratio for AD (Bertram et al., 2007; Carrasquillo et al., 2010; Table 1). Specifically, risk score was calculated based on $A P O E$ and $A P O J$ genotype by combining the natural log of the odds ratio for each participant to create a single risk score per participant. Values for the two risk alleles were added to generate an additive risk score. This risk scores then served as a regressor for volumetric measurements. The additive risk score was associated with higher right entorhinal cortex volume, $\beta=5.10, F_{(55)}=5.47, p=0.023$, but not left entorhinal cortex volume, $p>0.1$. This effect persisted as a strong trend in the absence of the APOE- $\varepsilon 4 /$ non-APOJ-C group, $\beta=4.36$, $F_{(54)}=3.89, p=0.0537$. As a control measure, we also measured gray matter volume in one of the last areas affected by $\mathrm{AD}$ (primary visual cortex, V1). As anticipated, neither left $(\beta=0.3313$, $p=0.9117)$ nor right $(\beta=-0.6976, p=0.8168) \mathrm{V} 1$ volumes were correlated with risk score. Moreover, no APOE-genotype associated differences were observed in the left $(p=0.8115)$ or right $(p=0.8446) \mathrm{V} 1$. Overall, these results suggest the possibility that $\mathrm{AD}$ risk-related genes $A P O E$ and $A P O J$ additively affect brain volume in young people within the entorhinal cortex.

\section{DISCUSSION}

Apolipoprotein $\mathrm{E}$ is the strongest genetic risk factor for $\mathrm{AD}$, and the entorhinal cortex is one of the earliest brain regions to develop neuropathological lesions and atrophy in AD (Hyman et al., 1984; Gomez-Isla et al., 1996; Braak et al., 2011). Because pathogenesis of $\mathrm{AD}$ begins as early as two decades prior to the presentation of clinical symptoms (Bateman et al., 2012), it is plausible that a series of genetically-induced differences in brain structuresuch as entorhinal cortex volume-could accumulate with aging to increase vulnerability to $\mathrm{AD}$ later in life. Here, we assayed entorhinal cortex volume in a cohort of young adults to directly investigate whether $A P O E$ and $A P O J$ genetic $\mathrm{AD}$ risk alters the structure of this region in early adulthood. Apolipoprotein E- $\varepsilon 4$ carriers exhibited greater entorhinal cortex volume in the right hemisphere (Figure 1), and further analysis revealed that the $A P O J-C$ genotype was associated with higher bilateral entorhinal cortex volume in $A P O E-\varepsilon 4$ non-carriers (Figure 2). The highest risk group ( $A P O E-\varepsilon 4, A P O J-C)$ exhibited greater entorhinal cortex volume compared to the lowest risk group (non-APOE- $\varepsilon 4$, non- $A P O J-C$ ) (Figure 3). When additive odds ratios of $A P O E$ and $A P O J$ served as regressors for volumetric measurements, higher disease risk was associated with greater right entorhinal cortex volume.

Volumetric studies report conflicting results when examining MTL volume in APOE risk carriers depending on the experimental parameters. For instance, one study of infants 1-3 months old with family histories of schizophrenia found $A P O E$-associated differences in temporal lobe volume, including the hippocampus and entorhinal cortex (Knickmeyer et al., 2013). However, this effect was not seen in a follow up study with 6-25 month old infants with no family history of schizophrenia (Dean et al., 2014). Similarly, while some evidence has suggested that healthy $A P O E-\varepsilon 4$ positive adults exhibit decreased bilateral hippocampal volume (O'dwyer et al., 2012) and gray matter density in the right medial temporal region (Wishart et al., 2006), another study in young adults reported that $A P O E-\varepsilon 4$ carriers showed relative increases in volume in the vicinity of the hippocampus (Alexander et al., 2012). Further contributing to the controversy, other studies have suggested no differences in MTL volume by APOE genotype (Mondadori et al., 2007; Filippini et al., 2009; Dennis et al., 2010; Samuraki et al., 2012; Stein et al., 2012; Matura et al., 2014). Less research has focused on the lesser AD risk factor, $A P O J$, and its effect on MTL volume. The limited extant research has suggested no difference exists in the MTL by APOJ genotype (Bralten et al., 2011; Stein et al., 2012). A metaanalysis of GWAS including over 7000 cognitively normal subjects 
showed that APOJ genotype was not significantly associated with hippocampal volume (Stein et al., 2012). However, this study did not focus on young adults or target the entorhinal cortex specifically. While the APOJ-C risk allele has no significant effect on gray matter volume by whole brain analyses in young adults, a related risk gene, CR1, was associated with smaller local gray matter volume in the entorhinal cortex in a prior study (Bralten et al., 2011).

The inconsistency of extant evidence could be due to differences in age, gender, exclusion criteria, statistical methods, family history, and how each region of interest was defined across studies. Another explanation may be that the entorhinal cortex is a relatively small region within the MTL, and few studies explicitly target the entorhinal cortex. Thus, it is possible that changes in entorhinal cortex volume are not large enough to alter volume of the MTL as a whole. By specifically targeting the entorhinal cortex in our study, we were able to detect differences in this relatively small MTL structure that may have otherwise been below the threshold for detection.

Our results indicate that the effects of $A P O E$ and APOJ may be stronger in the right hemisphere. Medial temporal lobe asymmetry has been linked with $\mathrm{AD}$ and disease progression. For instance, $A P O E-\varepsilon 4$ carriers have thinner left entorhinal cortex compared to the right, while those without $A P O E-\varepsilon 4$ show this asymmetry in the presence of AD pathology (Donix et al., 2013). Individuals with subjective memory impairment had reduced volumes of the hippocampus and entorhinal cortex bilaterally (Striepens et al., 2010). However, APOE-\&4 carriers without this impairment performed better on episodic memory tests and had larger right hippocampal volumes, as opposed to those with impairment performing worse with smaller right hippocampal volumes (Striepens et al., 2011). Interestingly, differences in symmetry were also reported in delusional $\mathrm{AD}$ patients with greater right temporal horn sizes than left, while non-delusional patients did not show this asymmetry (Geroldi et al., 2000). Although asymmetry effects have not yet reported for APOJ, it is possible that $A P O E$ may work in conjunction with $A P O J$ to induce asymmetry.

With aging, reductions in MTL volume in the hippocampus and entorhinal cortex are correlated with cognitive decline in the elderly (Bergfield et al., 2010; Raz et al., 2010; Varon et al., 2011). However, reductions in gray matter volume during the course of brain development in adolescence and early adulthood, correlate with increased synaptic pruning (Gogtay et al., 2004). Thus, increased entorhinal cortex volume during this developmental window could indicate a deficit in neural efficiency. Our study involved individuals of an average age of 21.8 years old, all of whom are at these later stages of brain development. Prior evidence has linked the APOJ-C risk allele to abnormal brain development through decreased white matter integrity (Braskie et al., 2011) and subsequent altered coupling between the hippocampus and prefrontal cortex during memory processing, mirroring disrupted connectivity in patients (Erk et al., 2011). Other evidence has also linked $A P O E-\varepsilon 4$ to abnormal brain structural and functional development in young risk allele carriers, suggesting that $A P O E$ and $A P O J$ risk may impede the pruning process in the entorhinal cortex.
Alternatively, these findings could contribute to evidence suggesting that the $A P O E$ and $A P O J$ risk genes confer an evolutionary advantage early in life, but confer a disadvantage later in life by increasing $\mathrm{AD}$ risk. This antagonistic pleiotropy hypothesis of $A P O E$ and $A P O J$ risk has been proposed in other contexts (e.g., see Tuminello and Han, 2011; Stevens et al., 2014). College-aged young adults carrying the $A P O E-\varepsilon 4$ allele have an advantage in verbal fluency, decision making, and memory (Zetterberg et al., 2009; Marchant et al., 2010; Jochemsen et al., 2012; Rusted et al., 2013; Green et al., 2014), but these advantages disappear by middle age and give way to impairment in old age. These beneficial effects early in life could be due in part to increased volume in the entorhinal cortex, allowing for more effective processing of memory-associated information.

Finally, larger entorhinal cortex volume in APOE and APOJ risk carriers could indicate more neuroinflammation in the entorhinal cortex of young adults. It has been postulated that $A P O E-\varepsilon 4$ may increase neuroinflammation during aging, thus increasing susceptibility to dementia later in life (e.g., for review, see Guo et al., 2004; Kim et al., 2009). Several studies have also linked APOJ-C risk to decreased CLU levels (Schurmann et al., 2011), which are thought to serve an anti-inflammatory role (Savkovic et al., 2007). Glia can contribute to half of brain volume changes (Snell, 2009), and studies have shown that APOE- 44 is associated with increased neuroinflammation (Guo et al., 2004; Chen et al., 2005; Maezawa et al., 2006; Zhu et al., 2012). Because the entorhinal cortex is one of the earliest affected brain areas in $\mathrm{AD}$, it is possible that the increase in entorhinal cortex volume could be due to a deficit in $A P O E$ and $A P O J$ carriers to control neuroinflammation in the young adult brain.

Overall, our findings in a young adult cohort indicate an additive effect of two of the strongest $\mathrm{AD}$ risk factors on a brain locus at the epicenter of $\mathrm{AD}$ pathogenesis. Entorhinal cortex volume increased as a function of increasing $A P O E$ and APOJ genetic $\mathrm{AD}$ risk. These results contribute to a growing literature characterizing genetic markers of $\mathrm{AD}$ risk in the young brain, long before the first overt signals of Alzheimer's appear. Thus, these findings inform our understanding of the role of these genetic risk factors in the normal brain, and contribute to the development of biomarker targets for future preventive $\mathrm{AD}$ therapies.

\section{ACKNOWLEDGMENTS}

This work was supported by NIH R01 AG035379, P01 AG030128 (G. William Rebeck), grants from Partners in Research and the American Legacy Foundation (Adam E. Green), and NIH NINDS 5T32NS041218 (Amanda M. DiBattista). Samples from the National Cell Repository for Alzheimer's Disease, which receives government support under a cooperative agreement grant U24 AG21886 awarded by the National Institute on Aging, were used in this study.

\section{REFERENCES}

Alexander, G. E., Bergfield, K. L., Chen, K., Reiman, E. M., Hanson, K. D., Lin, L., et al. (2012). Gray matter network associated with risk for Alzheimer's disease in young to middle-aged adults. Neurobiol. Aging 33, 2723-2732. doi: 10.1016/j. neurobiolaging.2012.01.014

Ashburner, J. (2007). A fast diffeomorphic image registration algorithm. Neuroimage 38, 95-113. doi: 10.1016/j.neuroimage.2007.07.007 
Ashburner, J., and Friston, K. J. (2000). Voxel-based morphometry-the methods. Neuroimage 11, 805-821. doi: 10.1006/nimg.2000.0582

Bateman, R. J., Xiong, C., Benzinger, T. L., Fagan, A. M., Goate, A., Fox, N. C., et al. (2012). Clinical and biomarker changes in dominantly inherited Alzheimer's disease. N. Engl. J. Med. 367, 795-804. doi: 10.1056/NEJMoa1202753

Bergfield, K. L., Hanson, K. D., Chen, K., Teipel, S. J., Hampel, H., Rapoport, S. I., et al. (2010). Age-related networks of regional covariance in MRI gray matter: reproducible multivariate patterns in healthy aging. Neuroimage 49, 1750-1759. doi: 10.1016/j.neuroimage.2009.09.051

Bertram, L., Mcqueen, M. B., Mullin, K., Blacker, D., and Tanzi, R. E. (2007). Systematic meta-analyses of Alzheimer disease genetic association studies: the AlzGene database. Nat. Genet. 39, 17-23. doi: 10.1038/ng1934

Braak, H., Thal, D. R., Ghebremedhin, E., and Del Tredici, K. (2011). Stages of the pathologic process in Alzheimer disease: age categories from 1 to 100 years. $J$. Neuropathol. Exp. Neurol. 70, 960-969. doi: 10.1097/nen.0b013e318232a379

Bralten, J., Franke, B., Arias-Vasquez, A., Heister, A., Brunner, H. G., Fernandez, G., et al. (2011). CR1 genotype is associated with entorhinal cortex volume in young healthy adults. Neurobiol. Aging 32, 2106.e7-2106.e11. doi: 10.1016/j. neurobiolaging.2011.05.017

Braskie, M. N., Jahanshad, N., Stein, J. L., Barysheva, M., Mcmahon, K. L., De Zubicaray, G. I., et al. (2011). Common Alzheimer's disease risk variant within the CLU gene affects white matter microstructure in young adults. J. Neurosci. 31, 6764-6770. doi: 10.1523/JNEUROSCI.5794-10.2011

Carrasquillo, M. M., Belbin, O., Hunter, T. A., Ma, L., Bisceglio, G. D., Zou, F., et al. (2010). Replication of CLU, CR1 and PICALM associations with alzheimer disease. Arch. Neurol. 67, 961-964. doi: 10.1001/archneurol.2010.147

Chen, S., Averett, N. T., Manelli, A., Ladu, M. J., May, W., and Ard, M. D. (2005). Isoform-specific effects of apolipoprotein $\mathrm{E}$ on secretion of inflammatory mediators in adult rat microglia. J. Alzheimers Dis. 7, 25-35.

Dean, D. C. 3rd, Jerskey, B. A., Chen, K., Protas, H., Thiyyagura, P., Roontiva, A., et al. (2014). Brain differences in infants at differential genetic risk for lateonset alzheimer disease: a cross-sectional imaging study. JAMA Neurol. 71, 1122. doi: 10.1001/jamaneurol.2013.4544

Demattos, R. B., Cirrito, J. R., Parsadanian, M., May, P. C., O’dell, M. A., Taylor, J. W., et al. (2004). ApoE and clusterin cooperatively suppress Abeta levels and deposition: evidence that ApoE regulates extracellular Abeta metabolism in vivo. Neuron 41, 193-202. doi: 10.1016/s0896-6273(03)00850-x

Dennis, N. A., Browndyke, J. N., Stokes, J., Need, A., Burke, J. R., Welsh-Bohmer, K. A., et al. (2010). Temporal lobe functional activity and connectivity in young adult APOE varepsilon4 carriers. Alzheimers Dement. 6, 303-311. doi: 10.1016/j. jalz.2009.07.003

Donix, M., Burggren, A. C., Scharf, M., Marschner, K., Suthana, N. A., Siddarth, P., et al. (2013). APOE associated hemispheric asymmetry of entorhinal cortical thickness in aging and Alzheimer's disease. Psychiatry Res. 214, 212-220. doi: 10. 1016/j.pscychresns.2013.09.006

Eickhoff, S. B., Stephan, K. E., Mohlberg, H., Grefkes, C., Fink, G. R., Amunts, K., et al. (2005). A new SPM toolbox for combining probabilistic cytoarchitectonic maps and functional imaging data. Neuroimage 25, 1325-1335. doi: 10.1016/j. neuroimage.2004.12.034

Eisenberg, D. T., Kuzawa, C. W., and Hayes, M. G. (2010). Worldwide allele frequencies of the human apolipoprotein E gene: climate, local adaptations and evolutionary history. Am. J. Phys. Anthropol. 143, 100-111. doi: 10.1002/ajpa. 21298

Elliott, D. A., Weickert, C. S., and Garner, B. (2010). Apolipoproteins in the brain: implications for neurological and psychiatric disorders. Clin. Lipidol. 51, 555573. doi: $10.2217 / \mathrm{clp} \cdot 10.37$

Erk, S., Meyer-Lindenberg, A., Opitz von Boberfeld, C., Esslinger, C., Schnell, K., Kirsch, P., et al. (2011). Hippocampal function in healthy carriers of the CLU Alzheimer's disease risk variant. J. Neurosci. 31, 18180-18184. doi: 10. 1523/jneurosci.4960-11.2011

Farrer, L. A., Cupples, L. A., Haines, J. L., Hyman, B., Kukull, W. A., Mayeux, R., et al. (1997). Effects of age, sex and ethnicity on the association between apolipoprotein E genotype and Alzheimer disease. A meta-analysis. APOE and Alzheimer Disease Meta Analysis Consortium. JAMA 278, 1349-1356. doi: 10. 1001/jama.278.16.1349

Fei, M., and Jianhua, W. (2013). Apolipoprotein epsilon4-allele as a significant risk factor for conversion from mild cognitive impairment to Alzheimer's disease: a meta-analysis of prospective studies. J. Mol. Neurosci. 50, 257-263. doi: 10. 1007/s12031-012-9934-y
Filippini, N., Rao, A., Wetten, S., Gibson, R. A., Borrie, M., Guzman, D., et al. (2009). Anatomically-distinct genetic associations of APOE epsilon4 allele load with regional cortical atrophy in Alzheimer's disease. Neuroimage 44, 724-728. doi: 10.1016/j.neuroimage.2008.10.003

Geroldi, C., Laakso, M. P., Decarli, C., Beltramello, A., Bianchetti, A., Soininen, H., et al. (2000). Apolipoprotein E genotype and hippocampal asymmetry in Alzheimer's disease: a volumetric MRI study. J. Neurol. Neurosurg. Psychiatry 68, 93-96. doi: 10.1136/jnnp.68.1.93

Gogtay, N., Giedd, J. N., Lusk, L., Hayashi, K. M., Greenstein, D., Vaituzis, A. C., et al. (2004). Dynamic mapping of human cortical development during childhood through early adulthood. Proc. Natl. Acad. Sci. U S A 101, 8174-8179. doi: 10.1073/pnas.0402680101

Golenkina, S. A., Gol'tsov, A., Kuznetsova, I. L., Grigorenko, A. P., Andreeva, T. V., Reshetov, D. A., et al. (2010). Analysis of clusterin gene (CLU/APOJ) polymorphism in Alzheimer's disease patients and in normal cohorts from Russian populations. Mol. Biol. (Mosk) 44, 620-626.

Gomez-Isla, T., West, H. L., Rebeck, G. W., Harr, S. D., Growdon, J. H., Locascio, J. J., et al. (1996). Clinical and pathological correlates of apolipoprotein E epsilon 4 in Alzheimer's disease. Ann. Neurol. 39, 62-70. doi: 10.1002/ana.4103 90110

Green, A. E., Gray, J. R., Deyoung, C. G., Mhyre, T. R., Padilla, R., Dibattista, A. M., et al. (2014). A combined effect of two Alzheimer's risk genes on medial temporal activity during executive attention in young adults. Neuropsychologia 56C, 1-8. doi: 10.1016/j.neuropsychologia.2013.12.020

Guo, L., Ladu, M. J., and Van Eldik, L. J. (2004). A dual role for apolipoprotein E in neuroinflammation: anti- and pro-inflammatory activity. J. Mol. Neurosci. 23, 205-212. doi: 10.1385/jmn:23:3:205

Harold, D., Abraham, R., Hollingworth, P., Sims, R., Gerrish, A., Hamshere, M. L., et al. (2009). Genome-wide association study identifies variants at CLU and PICALM associated with Alzheimer's disease. Nat. Genet. 41, 1088-1093. doi: 10. 1038/ng.440

Holtzman, D. M., Herz, J., and Bu, G. (2012). Apolipoprotein E and apolipoprotein E receptors: normal biology and roles in Alzheimer disease. Cold Spring Harb. Perspect. Med. 2:a006312. doi: 10.1101/cshperspect.a006312

Hyman, B. T., Van Hoesen, G. W., Damasio, A. R., and Barnes, C. L. (1984). Alzheimer's disease: cell-specific pathology isolates the hippocampal formation. Science 225, 1168-1170. doi: 10.1126/science.6474172

Jochemsen, H. M., Muller, M., van der Graaf, Y., and Geerlings, M. I. (2012). APOE epsilon4 differentially influences change in memory performance depending on age. The SMART-MR study. Neurobiol. Aging 33, 832.e15-832.e22. doi: 10. 1016/j.neurobiolaging.2011.07.016

Kang, S. W., Shin, Y. J., Shim, Y. J., Jeong, S. Y., Park, I. S., and Min, B. H. (2005). Clusterin interacts with SCLIP (SCG10-like protein) and promotes neurite outgrowth of PC12 cells. Exp. Cell Res. 309, 305-315. doi: 10.1016/j.yexcr.2005. 06.012

Kim, J., Basak, J. M., and Holtzman, D. M. (2009). The role of apolipoprotein E in Alzheimer's disease. Neuron 63, 287-303. doi: 10.1016/j.neuron.2009. 06.026

Knickmeyer, R. C., Wang, J., Zhu, H., Geng, X., Woolson, S., Hamer, R. M., et al. (2013). Common variants in psychiatric risk genes predict brain structure at birth. Cereb. Cortex 24, 2721-2731. doi: 10.1093/cercor/bht125

Koch, S., Donarski, N., Goetze, K., Kreckel, M., Stuerenburg, H. J., Buhmann, C., et al. (2001). Characterization of four lipoprotein classes in human cerebrospinal fluid. J. Lipid Res. 42, 1143-1151.

Kounnas, M. Z., Loukinova, E. B., Stefansson, S., Harmony, J. A., Brewer, B. H., Strickland, D. K., et al. (1995). Identification of glycoprotein 330 as an endocytic receptor for apolipoprotein J/clusterin. J. Biol. Chem. 270, 13070-13075. doi: 10. $1074 /$ jbc.270.22.13070

Lambert, J. C., Heath, S., Even, G., Campion, D., Sleegers, K., Hiltunen, M., et al. (2009). Genome-wide association study identifies variants at CLU and CR1 associated with Alzheimer's disease. Nat. Genet. 41, 1094-1099. doi: 10.1038/ ng. 439

Leeb, C., Eresheim, C., and Nimpf, J. (2014). Clusterin is a ligand for apolipoprotein E receptor 2 (ApoER2) and very low density lipoprotein receptor (VLDLR) and signals via the Reelin-signaling pathway. J. Biol. Chem. 289, 4161-4172. doi: 10. 1074/jbc.m113.529271

Maezawa, I., Maeda, N., Montine, T. J., and Montine, K. S. (2006). Apolipoprotein E-specific innate immune response in astrocytes from targeted replacement mice. J. Neuroinflammation 3:10. doi: 10.1186/1742-2094-3-10 
Marchant, N. L., King, S. L., Tabet, N., and Rusted, J. M. (2010). Positive effects of cholinergic stimulation favor young APOE epsilon4 carriers. Neuropsychopharmacology 35, 1090-1096. doi: 10.1038/npp.2009.214

Matura, S., Prvulovic, D., Jurcoane, A., Hartmann, D., Miller, J., Scheibe, M., et al. (2014). Differential effects of the ApoE4 genotype on brain structure and function. Neuroimage 89, 81-91. doi: 10.1016/j.neuroimage.2013.11.042

Mondadori, C. R., de Quervain, D. J., Buchmann, A., Mustovic, H., Wollmer, M. A., Schmidt, C. F., et al. (2007). Better memory and neural efficiency in young apolipoprotein E epsilon 4 carriers. Cereb. Cortex 17, 1934-1947. doi: 10. 1093/cercor/bhl103

Nathan, B. P., Bellosta, S., Sanan, D. A., Weisgraber, K. H., Mahley, R. W., and Pitas, R. E. (1994). Differential effects of apolipoproteins E3 and E4 on neuronal growth in vitro. Science 264, 850-852. doi: 10.1126/science.8171342

O'dwyer, L., Lamberton, F., Matura, S., Tanner, C., Scheibe, M., Miller, J., et al. (2012). Reduced hippocampal volume in healthy young ApoE4 carriers: an MRI study. PLoS One 7:e48895. doi: 10.1371/journal.pone.0048895

Raz, N., Ghisletta, P., Rodrigue, K. M., Kennedy, K. M., and Lindenberger, U. (2010). Trajectories of brain aging in middle-aged and older adults: regional and individual differences. Neuroimage 51, 501-511. doi: 10.1016/j.neuroimage. 2010.03.020

Reinvang, I., Espeseth, T., and Westlye, L. T. (2013). APOE-related biomarker profiles in non-pathological aging and early phases of Alzheimer's disease. Neurosci. Biobehav. Rev. 37, 1322-1335. doi: 10.1016/j.neubiorev.2013. 05.006

Risacher, S. L., Shen, L., West, J. D., Kim, S., Mcdonald, B. C., Beckett, L. A., et al. (2010). Longitudinal MRI atrophy biomarkers: relationship to conversion in the ADNI cohort. Neurobiol. Aging 31, 1401-1418. doi: 10.1016/j.neurobiolaging. 2010.04.029

Rusted, J. M., Evans, S. L., King, S. L., Dowell, N., Tabet, N., and Tofts, P. S. (2013). APOE e4 polymorphism in young adults is associated with improved attention and indexed by distinct neural signatures. Neuroimage 65, 364-373. doi: 10 . 1016/j.neuroimage.2012.10.010

Samuraki, M., Matsunari, I., Chen, W. P., Shima, K., Yanase, D., Takeda, N., et al. (2012). Glucose metabolism and gray-matter concentration in apolipoprotein E epsilon4 positive normal subjects. Neurobiol. Aging 33, 2321-2323. doi: 10. 1016/j.neurobiolaging.2011.11.020

Savkovic, V., Gantzer, H., Reiser, U., Selig, L., Gaiser, S., Sack, U., et al. (2007). Clusterin is protective in pancreatitis through anti-apoptotic and anti-inflammatory properties. Biochem. Biophys. Res. Commun. 356, 431-437. doi: 10.1016/j.bbrc.2007.02.148

Schurmann, B., Wiese, B., Bickel, H., Weyerer, S., Riedel-Heller, S. G., Pentzek, M., et al. (2011). Association of the Alzheimer's disease clusterin risk allele with plasma clusterin concentration. J. Alzheimers Dis. 25, 421-424. doi: 10. 3233/JAD-2011-110251

Shen, L., Kim, S., Risacher, S. L., Nho, K., Swaminathan, S., West, J. D., et al. (2010). Whole genome association study of brain-wide imaging phenotypes for identifying quantitative trait loci in MCI and AD: a study of the ADNI cohort. Neuroimage 53, 1051-1063. doi: 10.1016/j.neuroimage.2010.01.042

Snell, R. S. (2009). Clinical Neuro-Anatomy. 7th Edn. Philadelphia: Lippincott, Williams \& Wilkins, 104.

Stein, J. L., Medland, S. E., Vasquez, A. A., Hibar, D. P., Senstad, R. E., Winkler, A. M., et al. (2012). Identification of common variants associated with human hippocampal and intracranial volumes. Nat. Genet. 44, 552-561. doi: 10. 1038/ng. 2250

Stevens, B. W., Dibattista, A. M., William Rebeck, G., and Green, A. E. (2014). A gene-brain-cognition pathway for the effect of an Alzheimers risk gene on working memory in young adults. Neuropsychologia 61, 143-149. doi: 10.1016/j. neuropsychologia.2014.06.021

Striepens, N., Scheef, L., Wind, A., Meiberth, D., Popp, J., Spottke, A., et al. (2011). Interaction effects of subjective memory impairment and ApoE4 genotype on episodic memory and hippocampal volume. Psychol. Med. 41, 1997-2006. doi: $10.1017 /$ s0033291711000067

Striepens, N., Scheef, L., Wind, A., Popp, J., Spottke, A., Cooper-Mahkorn, D., et al. (2010). Volume loss of the medial temporal lobe structures in subjective memory impairment. Dement. Geriatr. Cogn. Disord. 29, 75-81. doi: 10. 1159/000264630

Thomann, P. A., Roth, A. S., Dos Santos, V., Toro, P., Essig, M., and Schroder, J. (2008). Apolipoprotein E polymorphism and brain morphology in mild cognitive impairment. Dement. Geriatr. Cogn. Disord. 26, 300-305. doi: 10. $1159 / 000161054$

Tuminello, E. R., and Han, S. D. (2011). The apolipoprotein E antagonistic pleiotropy hypothesis: review and recommendations. Int. J. Alzheimers Dis. 2011:726197. doi: 10.4061/2011/726197

Varon, D., Loewenstein, D. A., Potter, E., Greig, M. T., Agron, J., Shen, Q., et al. (2011). Minimal atrophy of the entorhinal cortex and hippocampus: progression of cognitive impairment. Dement. Geriatr. Cogn. Disord. 31, 276283. doi: 10.1159/000324711

Wishart, H. A., Saykin, A. J., Mcallister, T. W., Rabin, L. A., Mcdonald, B. C., Flashman, L. A., et al. (2006). Regional brain atrophy in cognitively intact adults with a single APOE epsilon4 allele. Neurology 67, 1221-1224. doi: 10.1212/01. wnl.0000238079.00472.3a

Zetterberg, H., Alexander, D. M., Spandidos, D. A., and Blennow, K. (2009). Additional evidence for antagonistic pleiotropic effects of APOE. Alzheimers Dement. 5:75. doi: 10.1016/j.jalz.2008.10.005

Zhu, Y., Nwabuisi-Heath, E., Dumanis, S. B., Tai, L. M., Yu, C., Rebeck, G. W., et al. (2012). APOE genotype alters glial activation and loss of synaptic markers in mice. Glia 60, 559-569. doi: 10.1002/glia.22289

Conflict of Interest Statement: The authors declare that the research was conducted in the absence of any commercial or financial relationships that could be construed as a potential conflict of interest.

Received: 30 May 2014; accepted: 14 September 2014; published online: 06 October 2014.

Citation: DiBattista AM, Stevens BW, Rebeck GW and Green AE (2014) Two Alzheimer's disease risk genes increase entorhinal cortex volume in young adults. Front. Hum. Neurosci. 8:779. doi: 10.3389/fnhum.2014.00779

This article was submitted to the journal Frontiers in Human Neuroscience.

Copyright $\odot 2014$ DiBattista, Stevens, Rebeck and Green. This is an open-access article distributed under the terms of the Creative Commons Attribution License (CC BY). The use, distribution and reproduction in other forums is permitted, provided the original author(s) or licensor are credited and that the original publication in this journal is cited, in accordance with accepted academic practice. No use, distribution or reproduction is permitted which does not comply with these terms. 